\title{
Electrical bioimpedance in patients after ischemic stroke, a civilization disease
}

\author{
Dorota Nalepa, ${ }^{1, A-F}$, Magdalena Czarkowska ${ }^{2, A-E}$, Wojciech Załuska ${ }^{3, D}$, Klaudia Jakubowska ${ }^{4, E-F}$, \\ Paweł Chruściel ${ }^{4, C-E}$ \\ ${ }^{1}$ Faculty of Social Sciencesband Humanities, State Higher Vocational School Memorial of Prof. Stanisław Tarnowski in \\ Tarnobrzeg, Poland \\ ${ }^{2}$ Insitute of Rural Heatlh, Lublin, Poland \\ ${ }^{3}$ II Faculty of Medicine with English Language Division, Lublin, Poland \\ ${ }^{4}$ Chair of Development in Nursing, Faculty of Health Sciences, Lublin, Poland \\ A - Research concept and design, B - Collection and/or assembly of data, C - Data analysis and interpretation, \\ $D$ - Writing the article, E-Critical revision of the article, F- Final approval of article
}

\begin{abstract}
Nalepa D, Czarkowska M, Załuska W, Jakubowska K, Chruściel P. Electrical bioimpedance in patients after ischemic stroke, a civilization
\end{abstract} disease. Ann Agric Environ Med. 2019; 26(1): 46-50. doi: 10.26444/aaem/84849

\begin{abstract}
Introduction. Ischemic stroke is caused by artery blockage, resulting in damage to brain tissue. A significant factor in the further treatment of a patient is not only the time to reach a specialist centre, but also the state of hydration of the organism. Clinical situations involving the excess or deficiency of water can have extremely serious consequences for the functioning of the body and subsequent stroke-related disorders. One of the increasingly common methods of evaluating the composition of the human body is by electrical bioimpedance.

Objective. The aim of the study was to assess the state of human body hydration measured by bioimpedance in patients with an early stage of ischemic stroke.

Methods and materials. The examination involved 81 patients with ischemic stroke in the Neurology Department, Subdivision of Stroke Treatment at the Province Specialist Hospital in Lublin, Poland, in 2015. Measurement of the composition and outer and intracellular space of the human body by the Whole Body Bioimpedance (WBIA) method was performed using the Body Composition Monitor (BCM) (Fresenius Medical Care GmbH, Bad Homburg, Germany).

Results. A group of patients were been examined with the use of the BIA apparatus three times: on the first, seventh, and tenth day of hospital stay, to determine the level of body hydration. Comparative analysis of data showed that on the first day of hospitalization all the measurements of electrical bioimpedance parameters in the patients were significantly different from those of the control group. In the case of TBW, ECW, ICW, the patients' scores were significantly higher than those of the control group. Only with respect to the over-hydration index, the patients achieved a significantly lower score than the control group.

Conclusions. Assessment of hydration status in patients with a diagnosed stroke indicates a slight dehydration in relation to the control group, but falling within the scope of normovolaemia, according to bioimpedance measurement standards.
\end{abstract}

\section{Key words}

cerebral stroke, electrical bioimpedance, hydration

\section{INTRODUCTION}

According to the WHO definition of 1980, cerebral stroke represents an unexpected occurrence of focal or global brain disorders with vascular abnormalities, lasting more than 24 hours. It is the second leading cause of death in the world after cardiovascular disease and the third cause of disability [1]. In Poland, stroke affects between 60,000 and 70,000 patients a year $[2,3]$. Factors that differentiate the incidence of cerebral disorders include, inter alia, age and gender $[4,5]$. Recent reports indicate that a significant factor in determining the course of stroke is the state of hydration of the patient. The clinical situations associated with excess and deficiency of water manifest themselves in the form of overhydration or dehydration respectively, and can have extremely dangerous consequences for the functioning of the body. Water accumulating in excess, in the intravascular

Address for correspondence: Magdalena Czarkowska, Insitute of Rural Heatlh, Jaczewskiego 2, 20-090 Lublin, Poland

e-mail: czarkowska.magdalena@imw.lublin.pl

Received: 21.11.2017; accepted: 28.01.2018; first published: 28.03.2018 and interstitial space can cause, inter alia, peripheral tissues oedema, pulmonary oedema, systemic pressure value, left ventricular hypertrophy. Evaluation of hydration is more and more dependent on a high-frequency electrical bioimpedance considered as a precise, non-invasive and inexpensive method.

\section{OBJECTIVE}

The aim of the study was to assess the state of hydration of the body measured by electrical bioimpedance in patients with an early stage of ischemic stroke.

\section{METHOD AND MATERIALS}

The examination involved 81 patients (41females, 40 males) in the Neurology Department, - Subdivision of Stroke Treatment at the Province Specialist Hospital in Lublin. Approval of the institutional authority was granted for the study. In addition, the research project received a positive opinion from the 
Bioethics Committee of the Medical University in Lublin (KE-0254/91/2015, dated 26 March 2015). All the patients (or their carers) were informed about the anonymity of the study and signed a consent to participate.

The patients were examined three times: on the first, seventh and tenth day of hospitalization - a total of 243 measurements. Each day of hospitalization involved the same measurements made oof the patients. The study applied the Whole Body Bioimpedance (WBI) method, using a Body Composition Monitor BCM) by Fresenius Medical Care $\mathrm{GmbH}$, Bad Homburg, Germany), and a set of $7.7 \times 1.9 \mathrm{~cm}^{2}$ electrodes, with a distance of $5 \mathrm{~cm}$ between the electrodes. The electrodes were applied to the hands and feet on the same side of the body. The measurements were takren under the following conditions:

- supine position;

- protection against the electric and magnetic fields;

- no contact with the metal frame of the bed;

- at Rest;

- at the temperature of $22^{\circ} \mathrm{C}$;

- upper limbs off the body at an angle of about $30^{\circ}$;

- lower limbs off the body at an angle of about $45^{\circ}$.

The electrical bioimpedance examination was also performed in the control group, which comprised 48 healthy volunteers aged 40-60 years (participants in the paramedic course).

\section{RESULTS}

The study group was tested with BIA three times: on the first, seventh, and tenth day of hospital stay to determine the level of body hydration. Comparative analysis of the data collected showed that on the first day of hospitalization all the measurements of electrical bioimpedance parameters were significantly different from those of the control group. In the case of Toptal Body Water (TBW), Extracellular Water (ECW) and Intracellular Water (ICW), patients had significantly higher scores than the control group. Only in terms of the over-ydration index, the patients had a significantly lower score than the control group (Tab. 1).

Data from the seventh day indicate that patients had similar TBW and ICW measurement scores. The over-hydration score was at the level of the control group score on the first day of the measurement. A statistically significant difference was still apparent in ECW measurement (a significantly higher score in the patients than in the control group). On the 10th day, the patients had a similar measurement score to the TBW and ICW measurement scores of the control group on the first day, while there was a statistically significant difference in ECW measurement (the patients had a higher score than the control group) (Tab. 2).

In the case of the over-hydration index measurement on the tenth day, the group of patients had a significantly higher score than the control group on the first day. Thus, on the first day, the over-hydration index in the control group was lower. On the seventh day, it was similar to the control group on the first day, and on the tenth day in the group of patients, the over-hydration index was higher than in the control group on the first day (Tab. 3).

There was a statistically significant difference in TBW between the seventh and tenth $(Z=2.021 ; \mathrm{p}=0.043)$ day. The mean value of TBW on the seventh day was $M=42.31$, and on tenth one $\mathrm{M}=40.96$. Thus, a more significant decrease in TBW occurred between the first and the tenth day $(\mathrm{Z}=1.964$; $p=0.049$ ), where on the first day $M=42.86$, and on the tenth - $M=40.96$. There was a statistically significant decrease in the TBW between the seventh and tenth day, and an even a greater decrease between the first and the tenth day, i.e. TBW was significantly reduced in subsequent measurements. There was no statistically significant difference between the first, the seventh and the tenth day in the level of ECW, but a significant difference appeared between the first and tenth day $(\mathrm{Z}=2.244 ; \mathrm{p}=0.025)$, where the mean value on the first day was $M=18.71$ and $M=19.30$ on the tenth. Thus, extracellular waterincreased between the first and the third measurement. There was no statistically significant difference in the ICW level between the first and the seventh day, even between the seventh and tenth, no difference was observed. On the other hand, between the first and the tenth day the difference in the ICW level was $Z=2.806 ; p=0.005$, where the average on the first day was $M=24.49$, and on the tenth day $-M=22.07$. Intracellular water decreased between the first and second measurement, as well as the first and the third measurement.

There were statistically significant differences in the overhydration index on individual days. Between the first and the seventh day $-Z=4.169 ; \mathrm{p}<0.001$; on the first day $-M=-0.69$; on the seventh day $-\mathrm{M}=0.34$. The difference between the seventh and the tenth day was $\mathrm{Z}=5.451 ; \mathrm{p}<0.001$, where the mean value was $M=0.34$ on the seventh day, and $M=1.50$ on the tenth. Between the first and the tenth day the difference was statistically significant at $\mathrm{Z}=6.427$; $\mathrm{p}<0.001$, where on the first day $\mathrm{M}=-0.69$, and on the tenth day $-\mathrm{M}=1.50$. It is important to emphasize that the over-hydration index increased considerably between subsequent measurements (Tab. 4).

Table 1. Analysis of bioimpedance indices in the primary and control group on the first day

\begin{tabular}{|c|c|c|c|c|c|c|c|c|c|}
\hline Bioimpedance index & Group & M & $\mathrm{Me}$ & Min & Max & Q1 & Q3 & SD & Statistical analysis \\
\hline \multirow{2}{*}{ TBW } & patients & 42.86 & 42.70 & 26.21 & 68.30 & 38.40 & 46.30 & 8.99 & \multirow{2}{*}{$\begin{array}{l}Z=3.952 \\
p<0.001\end{array}$} \\
\hline & control & 38.88 & 39.50 & 31.40 & 54.60 & 36.35 & 40.30 & 4.65 & \\
\hline \multirow{2}{*}{ ECW } & patients & 18.71 & 18.20 & 13.90 & 33.80 & 16.50 & 19.30 & 3.76 & \multirow{2}{*}{$\begin{array}{l}Z=2.808 \\
p=0.005\end{array}$} \\
\hline & control & 17.15 & 17.25 & 13.70 & 23.30 & 15.85 & 18.15 & 1.92 & \\
\hline ICW & patients & 24.49 & 24.80 & 12.20 & 41.60 & 21.10 & 26.70 & 6.33 & $\begin{array}{l}Z=3.014 \\
p=0.003\end{array}$ \\
\hline \multirow{2}{*}{ Overhydration index } & patients & -0.69 & -0.90 & -8.60 & 6.70 & -1.90 & 0.50 & 2.49 & \multirow{2}{*}{$\begin{array}{l}Z=-3.715 \\
p<0.001\end{array}$} \\
\hline & control & 0.28 & 0.65 & -1.40 & 1.80 & -0.70 & 0.90 & 0.91 & \\
\hline
\end{tabular}

M - mean; Me - median; Min - minimum score; Max - maximum score; Q1 - lower quartile; Q3 - upper quartile; SD - standard deviation; TBW - total body water; ECW - extracellular water; ICWintracellular water 
Table 2. Analysis of bioimpedance indices in the patient group and control groups on the seventh day

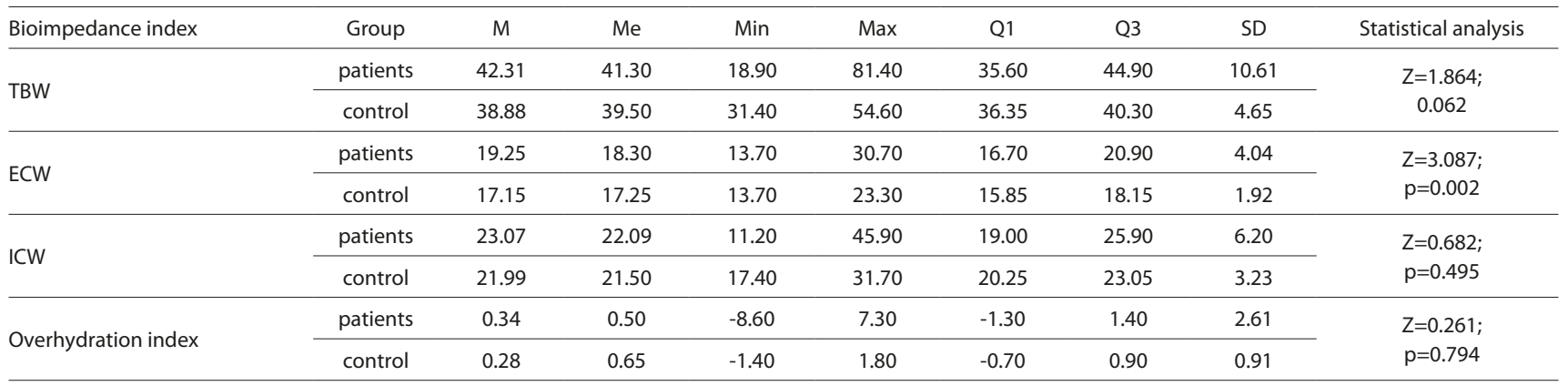

M - mean; Me - median; Min - minimum score; Max - maximum score; Q1 - lower quartile; Q3 - upper quartile; SD - standard deviation; TBW - total body water; ECW - extracellular water; ICWintracellular water

Table 3. Analysis of bioimpedance indices in the patient group and control groups on the tenth day

\begin{tabular}{|c|c|c|c|c|c|c|c|c|c|}
\hline Bioimpedance index & Group & M & Me & Min. & Max. & Q1 & Q3 & SD & Statistical analysis \\
\hline \multirow{2}{*}{ TBW } & patients & 40.96 & 39.60 & 25.80 & 62.30 & 36.40 & 43.10 & 8.30 & \multirow{2}{*}{$\begin{array}{l}Z=1.126 \\
p=0.260\end{array}$} \\
\hline & control & 38.88 & 39.50 & 31.40 & 54.60 & 36.35 & 40.30 & 4.65 & \\
\hline \multirow{2}{*}{ ECW } & patients & 19.30 & 18.35 & 13.00 & 30.20 & 17.40 & 20.90 & 3.76 & \multirow{2}{*}{$\begin{array}{l}Z=3.622 ; \\
p<0.001\end{array}$} \\
\hline & control & 17.15 & 17.25 & 13.70 & 23.30 & 15.85 & 18.15 & 1.92 & \\
\hline ICW & patients & 22.07 & 21.09 & 12.30 & 38.30 & 19.50 & 24.80 & 5.40 & $\begin{array}{c}Z=-0.534 \\
p=0.594\end{array}$ \\
\hline \multirow{2}{*}{ Overhydration index } & patients & 1.50 & 1.30 & -2.30 & 7.00 & 0.91 & 1.90 & 1.66 & \multirow{2}{*}{$\begin{array}{l}Z=5.637 \\
p<0.001\end{array}$} \\
\hline & control & 0.28 & 0.65 & -1.40 & 1.80 & -0.70 & 0.90 & 0.91 & \\
\hline
\end{tabular}

M - mean; Me - median; Min - minimum score; Max - maximum score; Q1 - lower quartile; Q3 - upper quartile; SD - standard deviation; TBW - total body water; ECW - extracellular water; ICWintracellular water

Table 4. Analysis of bioimpedance indices in the whole patient group on the first, seventh and tenth day

\begin{tabular}{|c|c|c|c|c|c|c|c|c|c|}
\hline Bioimpedance index & Day & M & Me & Min & Max & Q1 & Q3 & SD & Statistical analysis \\
\hline \multirow{4}{*}{ TBW } & 1. & 42.86 & 42.70 & 26.21 & 68.30 & 38.40 & 46.30 & 8.99 & \multirow{4}{*}{$\begin{array}{l}\text { Differences 1.-7: } \\
Z=0.638 ; p=0.524 \\
\text { Differences 7.-10: } \\
Z=2.021 ; p=0.043 \\
\text { Differences 1.-10: } \\
Z=1.964 ; p=0.049\end{array}$} \\
\hline & 7. & 42.31 & 41.30 & 18.90 & 81.40 & 35.60 & 44.90 & 10.61 & \\
\hline & & & & & & & & & \\
\hline & 10. & 40.96 & 39.60 & 25.80 & 62.30 & 36.40 & 43.10 & 8.30 & \\
\hline \multirow{3}{*}{ ECW } & 1. & 18.71 & 18.20 & 13.90 & 33.80 & 16.50 & 19.30 & 3.76 & \multirow{3}{*}{$\begin{array}{l}\text { Differences 1.-7.: } \\
Z=1.950 ; p=0.051 ; \\
\text { Differences 7.-10: } \\
Z=0.934 ; p=0.350 \\
\text { Differences 1.-10: } \\
Z=2.244 ; p=0.025\end{array}$} \\
\hline & 7. & 19.25 & 18.30 & 13.70 & 30.70 & 16.70 & 20.90 & 4.04 & \\
\hline & 10. & 19.30 & 18.35 & 13.00 & 30.20 & 17.40 & 20.90 & 3.76 & \\
\hline \multirow{2}{*}{ ICW } & 1. & 24.49 & 24.80 & 12.20 & 41.60 & 21.10 & 26.70 & 6.33 & \multirow{2}{*}{$\begin{array}{l}\text { Differences } 1-7: \\
Z=1.888 ; p=0.059 \\
\text { Differences } 7 .-10 \\
Z=1.227 ; p=0.220\end{array}$} \\
\hline & 7. & 23.07 & 22.09 & 11.20 & 45.90 & 19.00 & 25.90 & 6.20 & \\
\hline \multirow{3}{*}{ Overhydration index } & 1. & -0.69 & -0.90 & -8.60 & 6.70 & -1.90 & 0.50 & 2.49 & \multirow{2}{*}{$\begin{array}{l}\text { Differences 1.-7.: } \\
Z=4.169 ; p<0.001 \\
\text { Differences 7.-10 } \\
Z=5.451 ; p<0.001\end{array}$} \\
\hline & 7. & 0.34 & 0.50 & -8.60 & 7.30 & -1.30 & 1.40 & 2.61 & \\
\hline & 10. & 1.50 & 1.30 & -2.30 & 7.00 & 0.91 & 1.90 & 1.66 & $\begin{array}{l}Z=5.451 ; p<0.001 \\
\text { Differences 1.-10: } \\
Z=6.427 ; p<0.001\end{array}$ \\
\hline
\end{tabular}

M - mean; Me - median; Min - minimum score; Max - maximum score; Q1 - lower quartile; Q3 - upper quartile; SD - standard deviation; TBW - total body water; ECW - extracellular water; ICWintracellular water

\section{DISCUSSION}

Water as an integral component of any living organism constitutes $60 \%$ of the human body weight, and conditions the stability of the internal system at the organ, tissue and cellular level [6]. Water that accumulates in excess within the intravascular and interstitial spaces leads to many organ complications in a large group of patients. Proper hydration affects the brain plasticity mechanisms involved in the healing processes after stroke $[7,8]$.

The electrical bioimpedance technique as one of the methods of estimating the level of hydration is based on 
the theory of dielectric permittivity by mixed emulsified bodies. Its basic principle is that the electrical resistance of the cylinder remains directly proportional to its length, and inversely proportional to the cross-sectional area multiplied by the conductor density. The structure of the human body is treated as a sum of five cylinders. Low-frequency current (approx. $1 \mathrm{kHz}$ ) penetrates only the extracellular space, and at high frequencies it also penetrates into the interior of a cell [9]. Wabel et al. adopted fluid over load (FO) as the standard for reference values related to the hydration status - FO. Reference values were used for FO measurements in a group of 1,250 Caucasian patients with the use of BIS. The reference values in the control group are determined by FO quantities from $-1.1 \mathrm{~L}$ to $+1.1 \mathrm{~L}$ (ranging from 10 - 90 percentile) [10]. Today, bioelectric impedance is used in various fields of medicine, but also in pre-clinical studies on animals.

One of the first studies was conducted by Tamura et al. [11], where a method of inducing ischemic stroke was applied. Up to now, general cerebral ischemia or hemispheric stroke have been reported following the blockage of the central cerebral artery. In the Tamura et al. study, the occlusion of the middle cerebral artery allowed assessment of the dynamics of ischemic stroke, similar to the ischemic stroke occurring in the humans in question. The stroke was smaller in size, so that the differences between healthy brain tissue and ischemic tissue could be more closely followed. These studies, although very valuable, do not reflect the essence of ischemic changes during ischemic stroke. Another example may be the study by Wu et al., who performed measurements of rabbit encephalon impedance in vivo under conditions of homeostasis and ischemia. These studies used a two-terminal measurement at a frequency ranging from $0.1 \mathrm{~Hz}-1 \mathrm{MHz}$. The impedance of ischemic tissue was increased by $75 \%$ at frequencies lower than $10 \mathrm{~Hz}$, and in the range from $1 \mathrm{KHz}$ to $1 \mathrm{MHz}$ the value amounted to $15 \%$. Wu et al. also performed a four-channel measurement in the same frequency range. This showed a change in impedance whose statistical significance was less than 0.001 when ischemic stroke occurred [12]. These tests prove that the electrical impedance measurement of the brain is sensitive to changes, and can be an important aid in the qualification of patients with acute ischemic stroke.

In neurosurgery, the method of bioimpedance was applied in 2002 by Grasso et al. [13]. Their study involved patients with brain tumours, hydrocephalus and meningo-cerebral haemorrhage. They found significantly higher values of resistance and reactance in these patients, compared to the control group, while the phase angle did not show any significant differences.

Relatively few studies in Poland are devoted to assessing the state of hydration in patients with neurological diseases. The study on electrical bioimpedance measurements by Sokó 1 et al. [2] confirms the phenomena described by Lingwood et al. [2] that brain oedema increases the value of brain resistance [3]. Grasso et al. in their studies demonstrated impedance changes in meningo-cerebral haemorrhage and cerebral tumours accompanied by oedema [13], whereas Lingwood et al. observed a change in the bioimpedance value for oedema induced by hypoxia and ischemia [4]. Measurements performed by Sokół et al. reflect the dynamics of this process, namely, reduction in cerebral oedema (after anti-oedemic therapy) accompanied by a decrease in brain resistance value [2]. Both the experiments by Sokół et al. [2] and other scientists [4] confirm the validity of bioimpedance measurements to monitor changes undergoing in the edematous brain tissues. Liu et al. examined 51 patients hospitalized due to ischemic stroke [14], and a control group of 200 healthy volunteers. They demonstrated a statistically significant difference between patients after ischemic stroke and the control group. In addition, they observed a relationship between bioimpedance measurement and the time that passed from the occurrence of stroke symptoms. Resistance values were the highest between the third and fifth day of hospitalization, and after that, between the seventh and fourteenth day, they gradually decreased.

In own studies, the focus was placed on the evaluation of bioimpedance parameters during a10-day observation. Analysis of the hydration status of the patient group (n $=81)$ in relation to the control group $(n=48)$ showed that all the measurements of the bioimpedance indices in patients were significantly different from those of the control group. In the case of TBW, ECW and ICW, the patients had a significantly higher score than the control group. In the case of the over-hydration index, the patients had a significantly lower score $(M=-0.69)$ than the control group $(M=0.28)$. After examining the group of patients on the first, seventh and tenth day of hospitalization, the results of the bioimpedance indices analysis indicated a statistically significant decrease in TBW value between the seventh and tenth day, and an even a greater one between the first and the tenth day, i.e. the total body water decreased significantly in subsequent measurements. There was no statistically significant difference in the level of ECW between the first and the seventh and the tenth day, whereas a difference occurred between the first and the tenth day; therefore, the extracellular water increased between the first and the third measurement. The intracllular water decreased between the first and the second, and the first and third measurement. There were statistically significant differences in the overhydration index on individual days. It is crucial to highlight that the over-hydration index increased significantly between the subsequent measurements.

According to current literature on the importance of the supply of fluids, in an acute phase of stroke hydration is justified. Rescuing cerebral metabolism, and thus energy content in cerebral tissues, is accomplished by water entering the intercellular spaces and cells. Water, like a marker, signifies infarction focal points or small haemorrhage focal points, creating the so-called penumbra around them. Activating collateral circulation and local hydration (limited cerebral oedema) constitutes 'energy aids' from extracerebral organs and systems, the so-called 'extracerebral area'. Based on the above, the 'time is the brain' principle is being realized [5].

There is an increased risk of hypoosmotic and isoosmotic dehydration in the elderly, who are the largest age group in this study. The most common cause of excessive electrolyte depletion is pharmacotherapy with diuretics (thiazide or loop) inadequately adjusted to the age and clinical state of the patient [5]. For example, a study by Shimizu et al. in 2011 in a group of hospitalized elderly patients, showed that $44 \%$ of patients with hyperosmolar dehydration died, whilst only $17 \%$ died in the non-dehydrated group [15]. Bourdel-Marchasson et al. in similar studies estimated that geriatric mortality in the case of patients with inadequately treated hyperosmolar dehydration exceeds 50\% [6]. Patients who underwent self-testing between the first and tenth day received from $1,500-2,000 \mathrm{ml}$ of intravenous fluids per day 
(mainly saline solution), but no patient received blood and blood products.

\section{CONCLUSIONS}

1. In patients with a diagnosed stroke, the significantly higher total body water (TBW), extracellular water content (ECW), intracellular water content (ICW), as well as significantly lower values of overhydration index were found

2. In a comparative analysis between the first and the tenth day of monitoring, a statistically significant decrease in TBW value was observed, together with no statistically significant differences in ECW assessment and a significant increase in the over-hydration index

3. Assessment of hydration status in patients with a diagnosed stroke indicates a slight dehydration in relation to the control group, but falling within the normovolemia range according to bioimpedance measurement standards.

\section{REFERENCES}

1. Mazur R, Świerkocka M, Osiński G, Princ R. Zachowanie równowagi wewnątrzmózgowej w ostrej fazie udaru mózgu. Udar Mózgu. 2010; 12(1-2): 27-35.

2. Sokół B, Kot M, Łukomski T, Początek B, Jankowski R. Analiza wielokrotnych pomiarów bioimpedancji elektrycznej mózgu u chorych z obrzękiem mózgu. Nowiny Lek. 2006; 75: 311-314.

3. Lingwood BE, Kimble R, Dunster KR, Colditz PB, Ward LC. Noninvasive measurement of cerebral bioimpedance for detection of cerebral oedema in the neonatal piglet. Brain Res. 2002; 945: 97-10.

4. Lingwood BE, Dunster KR, Healy GN, Ward LC, Colditz PB. Cerebral impedance and neurological outcome following a mild or severe hypoxic/ischemic episode in neonatal piglets. Brain Res. 2003; 969: 160-167.

5. Faleńczyk K. Zapobieganie zaburzeniom wodnoelektrolitowym, odwodnieniu i niedożywieniu chorych $\mathrm{w}$ podeszłym wieku. In: Kędziora-Kornatowska K, Muszalik M, eds. Kompendium pielęgnowania pacjentów w starszym wieku. Czelej, Lublin 2007. p. 161-165.

6. Bourdel-Marchasson I, Barateau M, Rondeau V, Dequae-Merchadou L, Salles-Montaudon N, Emeriau JP, et al. A multi-center trial of the effects of oral nutritional supplementation in critically ill older inpatients. GAGE Group. Groupe Aquitain Geriatrique d'Evaluation. Nutrition. 2000; 16(1): 1-5.

7. Foley NC, Salter KL, Robertson J, Teasell RW, Woodbury MG. Which reported estimate of the prevalence of malnutrition after stroke is valid? Stroke. 2009; 40: 66-74.

8. Corrigan M, Escuro AA, Celestin J, Kirby DF. Nutrition in the stroke patient. Nut Clin Pract. 2011; 26: 242-252.

9. Van Biesen W, Williams JD, Covic AC, Fan S, Claes K, LichodziejewskaNiemierko M, et al. Fluid status in peritoneal dialysis patients: the European Body Composition 91 Monitoring (EuroBCM) study cohort. PloS one. 2011; 6(2): 17148.

10. Wabel P, Moissl U, Chamney P. et al. Towards improved cardiovascular management: the necessity of combining blood pressure and fluid overload. Nephrol Dialysis Transplantation. 2008; (23): 2965.

11. Tamura A, Graham Dl, McCulloch J, Teasdale GM. Focal cerebral ischaemia in therat: 1 . Description of technique and early neuropathological consequences following middle cerebral artery occlusion. J Cereb Blood Flow Metab. 1981; 1(1): 53-60.

12. Wu X, Dong X, Qin M, Fu F, Wang Y, You F, Xiang H, Liu R, Shi X. In vivo measurement of rabbits brain impedance frequency response and the elementary imaging of EIT. Sheng Wu Yi Xue Gong Cheng Xue Za Zhi. 2003; (20): 49-51.

13. Grasso G, Alafaci C, Passalacqua M, et al. Assesment of Human Brain Water Content by Cerebral Bioelectrical Impedance Analysis. A New Technique and lts Application to Cerebral Pathological Conditions. Neurosurgery. 2002; (50): 1064-1075.

14. Liu LX, Dong WW, Ji XM, Chen LH, Chen L, He W, Jia JP. A new method of noninvasive brain-edema monitoring in stroke: cerebral electrical impedance measurement. Neurol Res. 2006; 28: 31-37.

15. Shimizu M, Kinoshita K, Hattori K, et al. Physical signs of dehydration in the elderly. Intern Med (Tokyo). 2012; 51(10): 1207-1210. 